\title{
Determination of Serum CA125 and evaluate its efficiency as screening tool For Early Detection of Ovarian Tumors
}

\author{
Khalid A. Habib* \\ Maisaa G. Jumaa* \\ Munther J. Hussein** \\ Received 16, February, 2014 \\ Accepted 4, May, 2014
}

\begin{abstract}
:
Epithelial ovarian cancer is the leading cause of cancer deaths in women. To date, an effective screening tool for ovarian cancer has not been identified Several clinical and biological factors including serum cancer antigen 125 (CA- 125) have been assessed for prognostic and predictive relevance CA-125 is an epithelial marker derived from coelomic epithelium. It is elevated in $90 \%$ of advanced ovarian cancers and in $50 \%$ of early ovarian cancers while $20 \%$ of ovarian cancers have low or no expression of CA- 125

CA-125 concentrations were measured by Mini Vidas test (VIDAS CA125 II / BIOMERIEUX / France).

The median CA-125 levels were significantly higher in the sera of ovarian cancer patients than in those with benign tumors and in healthy controls. However in correlation with stages the results showed that Patients with stage II have highly significant differences in level of serum CA125 compare with stage I in and stage III. CA125 showed low sensitivity to detect stage I carcinoma of the ovary which limits its value as an initial screening tool therefore combining of CA125 with other markers might enable improved early detection of ovarian cancer as compared with use of this marker alone.
\end{abstract}

Key words: Ovarian cancer, CA125, Serum

\section{Introduction:}

Measurement of serum CA125 is the blood test most widely used to detect ovarian cancer. CA125 is a glycoprotein antigen. Elevated concentrations of CA125 are associated with malignant tumors of the pancreas, breast, lung, colon and ovary.[1] Menstruation and benign conditions such as endometriosis, pelvic inflammatory disease and liver disease can also be associated with elevated concentrations of CA125. CA125 may also be elevated in women with ascites, pleural or pericardial effusions and in women who have had a recent laparotomy.[2] Approximately $80 \%$ of patients with advanced ovarian cancer have elevated concentrations of CA125. A maximum of only $50 \%$ of patients with clinically detectable stage
I disease have elevated CA125 levels.[3] Despite its poor sensitivity and specificity, CA125 is most useful for detecting and monitoring nonmucinous epithelial tumours of the ovary.[4]

A good screening test must satisfactorily address validity, reliability, yield, cost, acceptance, and follow-up services. Most studies aimed at finding a screening test focus on sensitivity, specificity, and positive predictive value. Several clinical and biological factors including serum cancer antigen 125 (CA- 125) have been assessed for prognostic and predictive relevance [5].

CA-125 is a high molecular weight glycosylated membrane protein that can be detected in serum and is

\footnotetext{
*University of Baghdad College of Science for Women Biology Department

**University of London King 's College .London.UK.
} 
elevated in more than $80 \%$ of patients with ovarian cancer. CA-125 is an epithelial marker derived from coelomic epithelium.[6]. It is elevated in $90 \%$ of advanced ovarian cancers and in $50 \%$ of early ovarian cancers while $20 \%$ of ovarian cancers have low or no expression of CA- 125[7][8]. Any process that disrupts the epithelial lining of the peritoneum has the potential to raise the CA-125 level. Therefore, CA-125 can be elevated in many benign conditions including pregnancy, leiomyomata, ovarian cysts, endometriosis, appendicitis, and diverticulitis [9]. CA-125 can also be elevated in other cancers such as uterine, colon, lung, or pancreas. It is neither sensitive nor specific enough to screen for early disease in ovarian cancer [7]. Although one nested casecontrol study that included 37 women showed a sensitivity of $57 \%$ and specificity of $100 \%$ over 3 years [10], based on other data, the sensitivity of CA-125 for screening purposes is closer to $80 \%$ [9][10]. Currently, the only biomarker that has proven to detect ovarian cancer before the onset of clinical symptoms and is widely used in clinical practice is CA125 [11]. Serum CA125 levels has also been proposed to reflect the relative volume of the ovarian tumor, based on the results of previous clinical trials, but this has not been reproducible across studies [12]. Despite the benefits accompanying the use of CA125, many challenges exist that render it not as effective in early screening. One of the primary challenges is its decline in sensitivity in early-stage ovarian cancer [10].

A number of false-positive results could also occur, since levels of this marker are naturally increased with ovulation and may be elevated with endometriosis, fibroids, and many other benign conditions; therefore, this marker is more effective in postmenopausal women. In addition, cutoff levels $(35 \mathrm{U} / \mathrm{mL})$ that are used for identifying a positive CA125 test have only been established for patients with a clinical form of the disease. This value was not recommended for screening asymptomatic patients [12]. Currently, in some institutions, the screening strategy for ovarian cancer is annual pelvic examinations. Transvaginal ultrasound and serial measurements of the biomarker CA125 , have been included for the highrisk population, but with little success. CA-125 exhibits a sensitivity of less than $60 \%$ in early stages of the disease .Therefore, CA-125 may help raise an index of suspicion when evaluating a pelvic mass, but it is not sufficiently sensitive or specific for effective screening, thus, additional serum markers are required.

\section{Materials and Methods:}

The serum samples from 60 patients diagnosed with different types and stages of ovarian cancer, 15 patients with benign ovarian tumors, and 15 healthy controls were tested. Serum samples from patients with early-stage ovarian cancer, and women with benign pelvic disease, were provided by certain Iraqi hospitals(AlKadhemia , AL - Yarmouk Teaching Hospital and Baghdad Hospital, the Teaching Laboratories of Medical City, Nuclear Medical Hospital in Baghdad and Alsader Hospital in Missan). All the patients had provided their medical history and had undergone clinical and ultrasound examination of the pelvic organs before they were qualified for the study.

The average age of this group was 45.8 years and the range was $10-80$ years. The blood sample was dispensed in a plain tube, and left for 20 minutes at room temperature $\left(20-25^{\circ} \mathrm{C}\right)$ for clotting. Then, it was centrifuged at 
$3000 \mathrm{rpm}$ for 10 minutes to collect serum. The serum was divided into aliquots $(0.3 \mathrm{ml})$ and stored in the freezer $\left(-20^{\circ} \mathrm{C}\right)$ until use. CA125 levels were determined by MiniVidas test (VIDAS CA125 II / BIOMERIEUX / France) according to the recommendations of the manufacturer. The kits were designed to measure human CA125 levels in serum. The measurement range of VIDAS CA125 II $4-600 \mathrm{u} / \mathrm{ml}$. Concentrations were measured automatically calculated by VIDAS in relation to the calibration curve stored in memory and then printed out.

The aim of this study was to determine the serum levels of CA125 in healthy individual, patients with benign tumors and patients with malignant ovarian tumors. and evaluate its ability of using this marker for early detection of ovarian cancer.

\section{Statistical Analysis:}

The Statistical Analysis SystemSAS (2010) was used to effect of difference factors in study parameters or percentage. The least significant difference -LSD test used to the comparative between means in this study.

\section{Results:}

Our results showed that the level of serum CA-125 was statistically significantly higher in the patients with ovarian cancer (Mean \pm SE : $75.33 \pm$ 23.32; $\mathrm{p}$ value $=0.0452<0.05)$, than in patients with benign (Mean \pm SE : 9.71 \pm 2.08)tumors and healthy controls (Mean $\pm \mathrm{SE}: 12.70 \pm 2.97$ ) (figure1). Analysis was also performed on the following parameters: type of ovarian cancer (Epithelial tumors, Sex cordstromal tumors ,Germ cell tumor), histopathological subtypes of epithelial ovarian tumors(Serous tumors, Mucinous tumors, Endometroid tumors, Clear cell tumors, and burnner tumors) and FIGO stages (I,II,III). Statically high significant correlations were observed between elevated levels of CA125 and type of ovarian cancer, the epithelial ovarian tumors showed the highest level of CA125 (Mean: $68.034 \mathrm{u} / \mathrm{ml}, \mathrm{P}$ value $=0.0029<0.01$ ) compare with germ cell tumors (Mean \pm SE :31.90 \pm 18.10) and sex-cord tumors(Mean \pm SE: $10.09 \pm 2.14$ ) (figure2).Statically significant differences in serum level of CA125 in correlation with histopathological subtypes of epithelial ovarian tumors, the mucinous tumors showed highest level (Mean \pm SE: $137.20 \pm 23.39$, $\mathrm{P}=0.0244<0.05)$ as compared with other epithelial ovarian tumor types (Mean \pm SE: $75.27 \pm 18.54,32.25 \pm$ $9.96,55.65 \pm 0.00,39.80 \pm 28.40$ ) for Serous tumors, Endometriod tumors, Burnner tumors, Clear cell tumors respectively (figure3). The patterns of changes in the Inca serum CA-125 in the FIGO stages of ovarian cancer were compared with each other. Patients with stage two showed highly significant differences in level of serum CA125 (Mean \pm SE:278.64 \pm 34.19; $\mathrm{P}=0.0337<0.01)$ compare with stage I and II in which the CA125 serum level were (Mean \pm SE: $51.80 \pm$ $6.90,29.27 \pm 6.52$ ) respectively (figure4). According to the CA125 diagnostic kit the normal serum level is $35 \mathrm{u} / \mathrm{ml}$, we used this value as the cutoff to separate tumors into positive and negative results which showed that statically there was no significance differences between the samples were less than the normal value $(59.5 \%)$ and samples were more than the normal value $(40.5 \%)$ (figure5). For the patients with stage I, the using of cutoff value showed that statically high significance differences between the samples were less than the normal value $(63 \%)$ and the samples were more than the normal value (37\%) (figure6). 


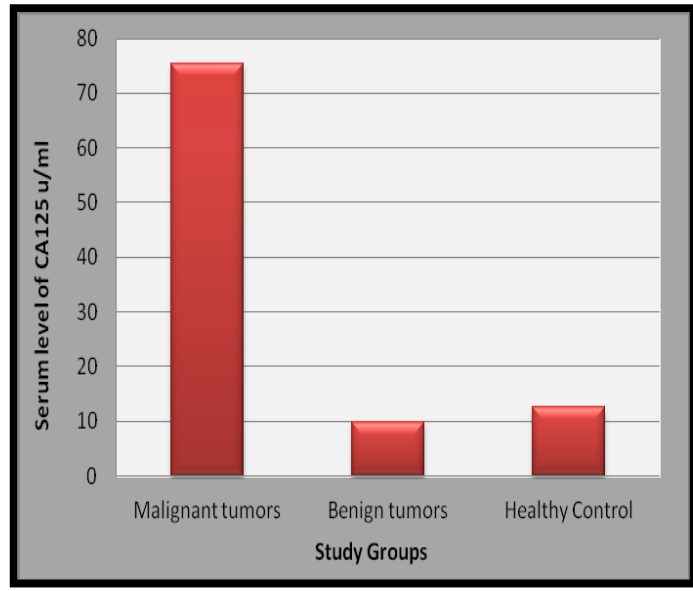

Fig. (1): Shows the serum level of CA-125 in groups of study. The level in ovarian cancer patients was higher than in patients with benign tumors and healthy controls

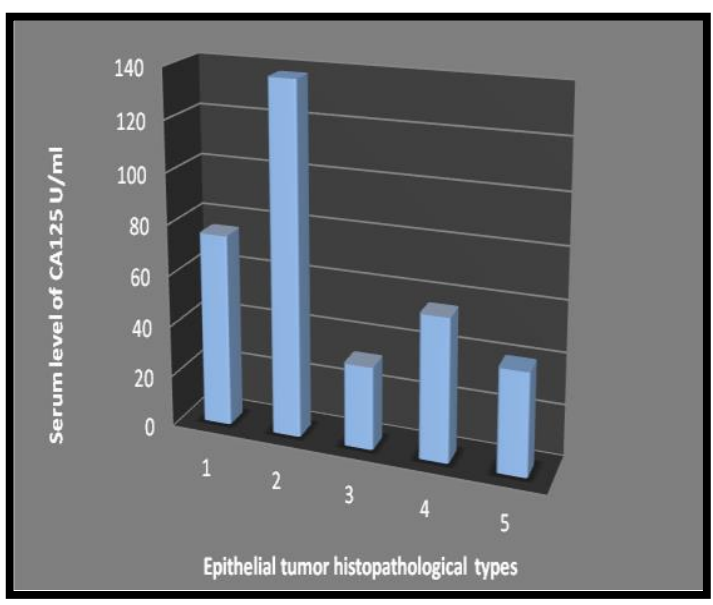

Fig. (3): The mean levels of serum CA-125 in the different Epithelial ovarian tumor types. (1). Serous tumors, (2) Mucinous tumors, (3) Endometriod tumors,(4) Burnner tumors ,(5) Clear cell tumors. the mucinous tumors showed highest level as compared with other epithelial ovarian tumor types.

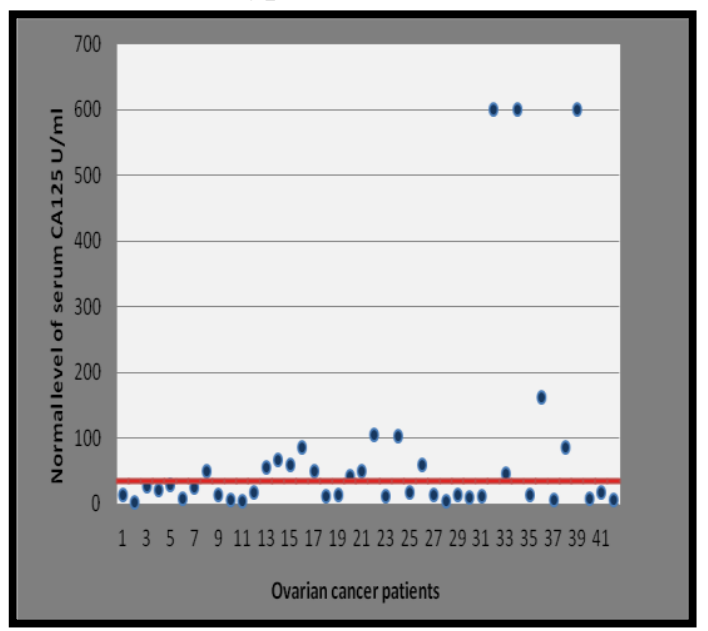

Fig.(5):The ovarian cancer samples were divided into positive and negative by using the value $35 \mathrm{u} / \mathrm{ml}$ as cutoff, which showed that $59.5 \%$ of samples were less than the cutoff value while $40.5 \%$ of samples were more than the cutoff value

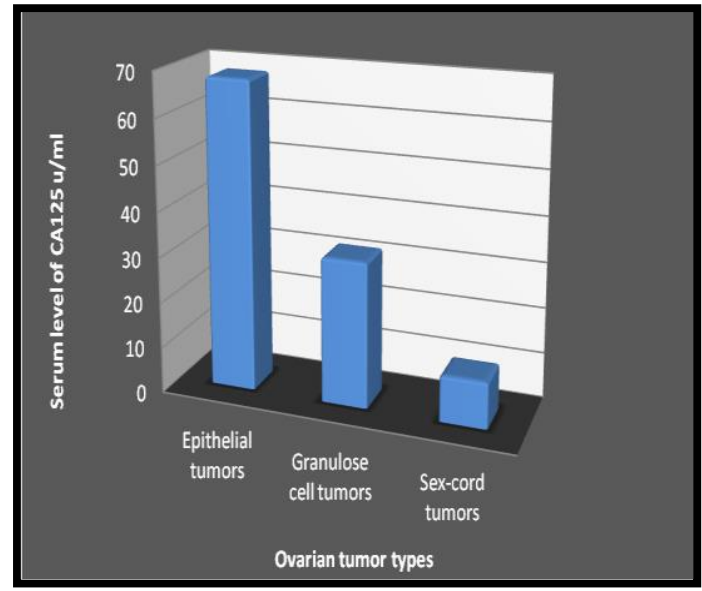

Fig. (2): Shows the serum level of CA-125 in the three types of ovarian cancer. The epithelial ovarian tumors were associated with the highest level of CA125

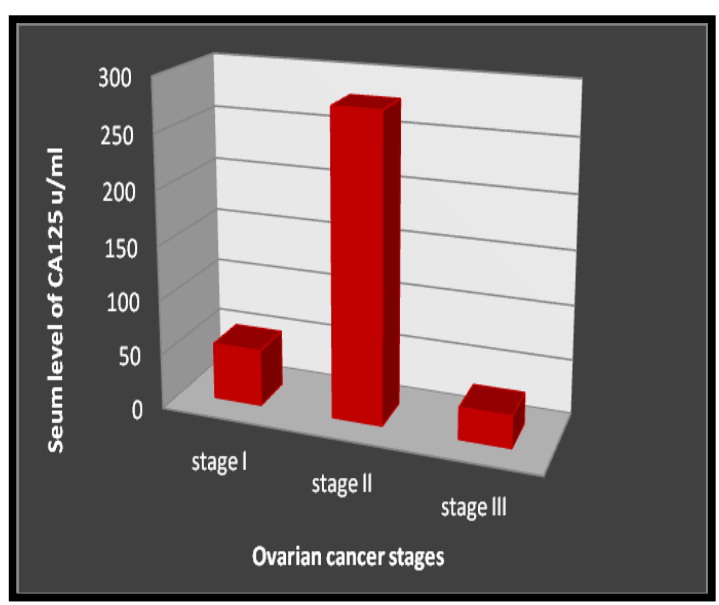

Fig.(4): The correlation between mean levels of serum CA-125 and stages of ovarian cancer. Patients with stage two showed the highest level of serum CA125 compare with stage I and II

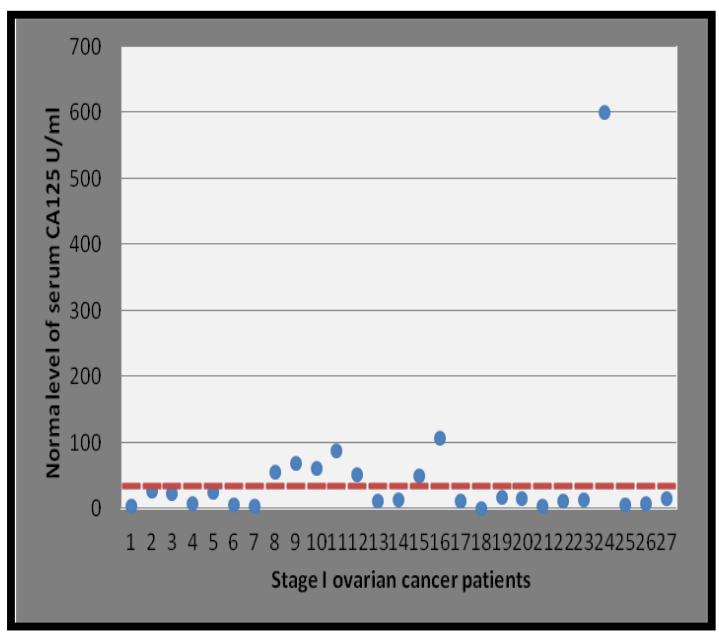

Fig.(6): The stag I ovarian cancer patients were divided into positive and negative by using the value $35 \mathrm{u} / \mathrm{ml}$ as cutoff, which showed that $63 \%$ of samples were less than the cutoff value while $37 \%$ of samples were more than the cutoff value. 


\section{Discussion:}

The results of this study showed that showed that CA125 was significantly increased in sera of ovarian cancer patients $(75.33 \mathrm{unit} / \mathrm{ml})$ when are compared to patients with benign tumors (9.71 unit $/ \mathrm{ml})$, and the healthy individuals (12.70 unit $/ \mathrm{ml})$, these results have the same similarities with Dawood ,2004 [13], who showed that CA125 was significantly increased in sera of ovarian cancer patients $(192 \pm 141 \mathrm{unit} / \mathrm{ml})$ when are compared to the healthy individuals $(27.8 \pm 5.4$ unit $/ \mathrm{ml}$ ) and pathological control (33.2 \pm 10.6 unit $/ \mathrm{ml}$ ). Our findings were also similar to that of Molina $e t$ al., 2011[14] who reported that significantly higher serum concentrations of CA 125 were found in patients with cancer than in those with benign diseases, and Lawicki et al.,2013[15], showed that Patients with ovarian cancer had statistically considerably higher levels CA125 with $\mathrm{p}$ value $<0.001$, than those observed in benign ovarian tumor patients.

In correlation with the types of ovarian cancer we type of ovarian cancer that statically high significant correlations between elevated levels of CA125 and type of ovarian cancer, the epithelial ovarian tumors showed the highest level of CA125 (Mean: 68.034 $\mathrm{u} / \mathrm{ml}$ )compare with germ cell tumors (Mean:31.90 u/ml) and sex-cord tumors(Mean:10.09 u/ml).These results reflect the fact that for sex-cord tumors CA125 is non-diagnostic, and other tumors markers such as oestradiol and inhibins (granulosa cell tumors), testosterone (Sertoli Leydig cell tumors)may be measured, while for germ cell tumors, tumor markers may not always be helpful but AFP, b-hCG and LDH should always be measured [16].

Statically significant differences in serum level of CA125i n correlation with histopathological subtypes of epithelial ovarian tumors, the mucinous tumors showed highest levels (Mean 137.20u/ml) as compared with other epithelial ovarian tumor types (Mean: 75.27, 32.25, 55.65, 39.80) for Serous tumors, Endometriod tumors, Burnner tumors, Clear cell tumors respectively. These results were different from that reported by Partheen et al.,2011 [17], who showed that the median levels of mucinous epithelial ovarian tumor were low in his study groups. Our results showed that the Serous tumors mean levels were higher than the mean levels of Endometriod tumors which similar to that reported by Lawicki et al.,2013 [15],who observed that statistical differences of the results for CA125 between groups with serous epithelial $(171.21 \mathrm{U} / \mathrm{ml})$ and endometrioid epithelial sub-types of ovarian cancer patients $(114.00 \mathrm{U} / \mathrm{ml})$.

CA-125 in the In relation with FIGO stages of ovarian cancer our results showed that Patients with stage II have highly significant differences in level of serum CA125 (Mean:278.64u/ml) compare with stage I in which the mean of CA125 serum level was (Mean: $51.80 \mathrm{u} / \mathrm{ml}$ ) and stage III (Mean: 29.27u/ml). Our results were similar to that reported by Lawicki et al.,2013 [15], who showed that significantly higher concentrations of CA125 in II-IV stages of ovarian cancer, he showed that CA125 levels in all groups of ovarian cancer patients were statistically significantly higher in comparison to the group of healthy subjects and patients with benign tumors except ovarian cancer patients with stage I. The using of $35 \mathrm{u} / \mathrm{ml}$ cutoff showed that that statically there was no significance differences between the samples that less than the normal value $(59.5 \%)$ and samples that more than the normal value (40.5\%) (figure), while for patients with stage I, the using of cutoff value 
showed that statically high significance differences between the samples that less than the normal value $(63 \%)$ and the samples that more than the normal value $(37 \%)$. The ability to detect early cancers would definitely improve patient prognosis. It was demonstrated that the diagnostic sensitivity increased with the progress of cancer disease and was the highest for CA125 (from $40 \%$ in stage I up to $84 \%$ in stage IV of the disease)[15]. the sensitivity of CA125 to detect stage I carcinoma of the ovary is only about 50\% [18], which limits its value as an initial screening tool. The potential implication of early detection of ovarian cancer on patient outcome is shown by the differential survival rates of women diagnosed at different stages of disease progression. The 10-year survival rate is nearly $90 \%$ when the disease is localized to the ovaries at the time of diagnosis and drops to $20 \%$ when the disease has spread to distant sites at the time of diagnosis [19]. Serum markers are useful tools for the diagnosis and follow up of patients with different forms of cancer [20]. Numerous proteins have been identified as specific markers for ovarian cancer either in blood or urine [21][22]. However, no single protein has provided adequate sensitivity and specificity. CA 125 is widely distributed on the surface of both healthy and malignant cells of mesothelial origin, including pleural, pericardial, peritoneal and endometrial cells, as well as in normal genital tract and amniotic membrane.

From results of this study we can concluded that combining of CA125 with other markers like VEGF and IL8 might enable improved early detection of ovarian cancer as compared with use of this marker alone.

\section{References:}

1. Bast R.C. Jr, Klug TL, St John E, Jenison E, Niloff JM, Lazarus $\mathrm{H}$. 1983. A radioimmunoassay using a monoclonal antibody to monitor the course of epithelial ovarian cancer. N Engl J Med; 309(45):883-7.

2. Sturgeon C. 2002. Practice guidelines for tumor markers use in the clinic. Clin Chem;48(8):1151-9.

3. Jacobs I., Bast R.C. Jr. The CA 125 tumour-associated antigen: a review of the literature. Hum Reprod 1989;4(1):1-12.

4. Kabawat S.E., Bast R.C., Welch W.R., Knapp R.C., Colvin R.B. 1983. Immunopathologic characterization of a monoclonal antibody that recognizes common surface antigens of human ovarian tumors of serous, endometrioid, and clear cell types. Am J Clin Pathol;79(1):98-104.

5. Gadducci A, Viacava P, Cosio S.2003. Intratumoral microvessel density, response to chemotherapy and clinical outcome of patients with advanced ovarian carcinoma. Anticancer Res. 23(1B):549-556.

6. Jacobs IJ, Menon U. 2004. Progress and challenges in screening for early detection of ovarian cancer. Mol Cell Proteomics. 3(4):355-366.

7. Bast RC Jr, Badgwell D, Lu Z, et al. 2005. New tumor markers: CA 125 and beyond. Int J Gynecol Cancer. 15(suppl 3):274-281.

8. Badgwell D, Bast RC Jr. 2007. Early detection of ovarian cancer. Dis Markers.23(5-6):397-410

9. Meany DL, Sokoll LJ, Chan DW. 2009. Early detection of cancer: immunoassays for plasma tumor markers. Expert Opin Med Diagn. 3(6):597- 605.

10. Helzlsouer KJ, Bush TL, Alberg AJ, et al. 1993. Prospective study of serum CA-125 levels as markers of ovarian cancer. JAMA. 269(9):11231126. 
11. Urban N. and C. Drescher.2008. "Potential and limitations in early diagnosis of ovarian cancer," in Ovarian Cancer: State of the Art and Future Directions in Translational Research, G. Coukos, A. Berchuck, and R. Ozols, Eds., pp. 3-14.

12. Skates S.J., Jacobs I.J., Knapp R.C. 2000. Tumor markers in screening for ovarian cancer," in Ovarian Cancer: Methods and Protocols, J.M. S. Bartlett, Ed., pp. 61-73.

13. Dawood M. BIOCHEMICAL STUDIES OF CA125, HCG and other biochemical parameters in patients with different types of ovarian cancer. Thesis 2004.

14. Molina R. \& Escudero J.M. \& Auge J.M., Filella X., Foj L., Torne A., Lejarcegui J., Pahisa J. 2011.HE4 a novel tumour marker for ovarian cancer: comparison with CA 125 and ROMA algorithm in patientswith gynaecological diseases. Tumor Biol.32:10871095.

15. Lawicki S, Grażyna E. B., Ewa G.-S. ,Maciej S.2013. The plasma concentration of VEGF, HE4 and CA125 as a new biomarkers panel in different stages and sub-types of epithelial ovarian tumors. Journal of Ovarian Research, 6:45

16. Reed N., D. Millan, R. Verheijen M. Castiglione. 2010. Nonepithelial ovarian cancer: ESMO Clinical Practice Guidelines for diagnosis, treatment and follow-up. Annals of Oncology 21 (Supplement 5): v31-v36.

17. Partheen K., Kristjansdottir B., Sundfeldt K. 2011. Evaluation of ovarian cancer biomarkers HE4 and CA-125 in women presenting with a suspicious cystic ovarian mass. J Gynecol Oncol Vol. 22, No. 4:244252.

18. Jacobs I., Davies A.P., Bridges J., Stabile I., Fay T., Lower A., Grudzinkas J.G. and Oram D.1993. Prevalence screening for ovarian cancer in postmenopausal women by CA125 measurement and ultrasonography. BMJ 306: 10301032

19. Chambers AF, Vanderhyden BC. 2006. Ovarian cancer biomarkers in urine. Clin Cancer Res 12:323-7.

20. Vitzthum F, Behrens F, Anderson NL, ShawJH. Proteomics 2005. frombasic research to diagnostic application. A review of requirements \& needs. J Proteome Res;4:1086-97.

21. Ye B, Skates S, Mok SC, et al.2006.Proteomic-based discovery and characterization of glycosylated eosinophil- derived neurotoxin and COOH-terminal osteopontin fragments for ovarian cancer in urine. Clin Cancer Res;12:432-41.

22. Goff BA, Muntz HG.2005. Screening and early diagnosis of ovarian cancer. Women's Health in Primary Care ;8:262-8. 


\section{تحديد المستوى المصلي للمستضد السرطاني 125 وتقييم كفاعته كوسيلة فحص لاور المصني للتشخيص المبكر لأورام المبيض}

منذر جعفر حسين***
ميساء غازي جمعة*

خالد عبل الرزاق حبيب

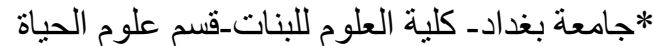
|جامعة لندن - الكلية الملكية _لندنـ المملكة المتحدة.

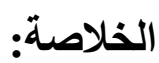

يعتبر سرطان المبيض الطلائي احد المسبيات المؤدية الى الموت من بين الامر اض النسائية. الى هذا التاريخ

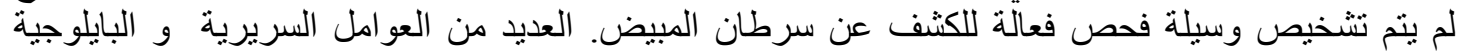

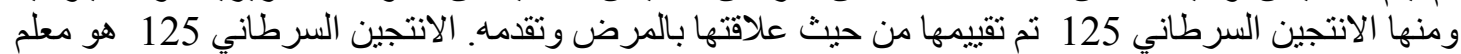

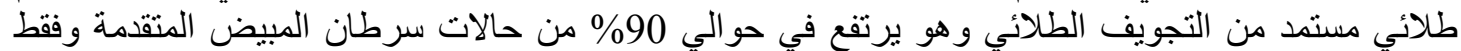

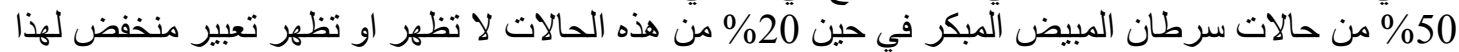

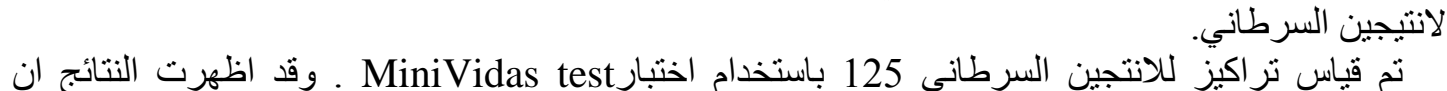

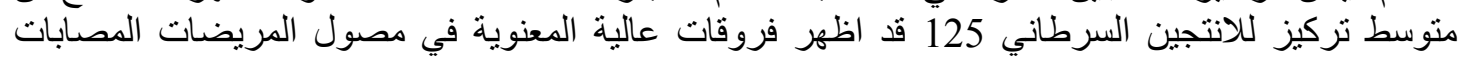

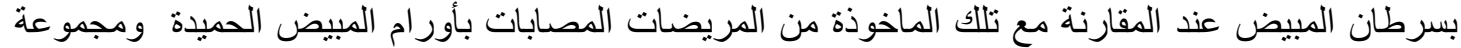

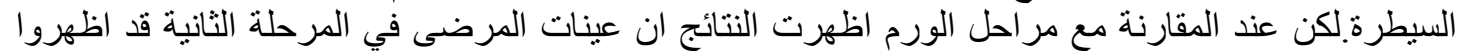

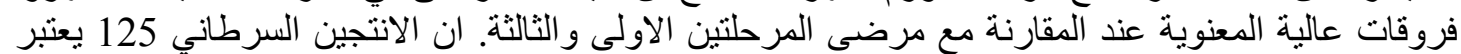

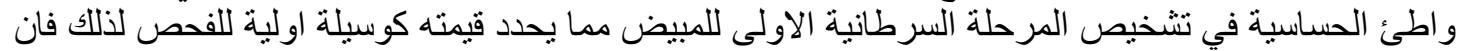
ارفاق الانتجين السرطاني 125 بمعلمات اخرى قد بساهم في تحسن عملية التثخيص المبكر لسرطان السيض المبيض

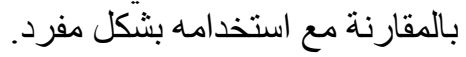

